\title{
QUANDO CHEGA O FIM? UMA REVISÃO NARRATIVA SOBRE TERMINALIDADE DO PERÍODO ESCOLAR PARA ALUNOS DEFICIENTES MENTAIS
}

\author{
Claudia de Souza Rodrigues Elias ${ }^{1}$; Leandro Andrade da Silva ${ }^{2}$; \\ Mirian Teresa de Sá Leitão Martins ${ }^{3}$; Neide Ana Pereira Ramos ${ }^{4}$; \\ Maria das Graças Gazel de Souza ${ }^{5}$; Rodrigo Leite Hipólito ${ }^{6}$
}

\begin{abstract}
O processo de inclusão de alunos deficientes possivelmente é um dos maiores impasses enfrentados pelos profissionais da área da educação, na atualidade. Faz-se necessária a criação de diferentes dispositivos educativos ou assistenciais, em face da terminalidade do período escolar, justamente para que as oportunidades futuras possam ser reais, e não concebidas como prática excludente. Este artigo objetivou apresentar e compreender o conceito de terminalidade específica, possibilitando reflexão sobre o processo educativo de pessoas deficientes. Trata-se de um estudo qualitativo, o qual utilizou a técnica de revisão narrativa como aporte metodológico. Os resultados apontam a necessidade da efetivação da terminalidade escolar, que possibilita a inclusão social de pessoas deficientes.
\end{abstract}

Descritores: Retardo Mental; Educação; Literatura de Revisão como Assunto.

\footnotetext{
${ }^{1}$ Especialista em Educação Especial - Deficiência Mental, Professor, Prefeitura Municipal de Rio Claro, RJ, Brasil. Professor, Prefeitura Municipal de Resende, RJ, Brasil. E-mail: rodrigues.elias@ig.com.br.

2 Enfermeiro, Terapeuta Ocupacional, Mestrando em Enfermagem, Universidade do Estado do Rio de Janeiro, RJ, Brasil. Professor, Universidade Federal do Estado do Rio de Janeiro, RJ, Brasil. E-mail: leandrotorj@yahoo.com.br.

3 Psicóloga, Mestre em Ciências Médicas, Universidade do Estado do Rio de Janeiro, RJ, Brasil. E-mail: mirianeresad@yahoo.com.br.

${ }^{4}$ Pedagoga, Mestre em Educação, Professor, Universidade Federal do Estado do Rio de Janeiro, RJ, Brasil. E-mail: neideana2004@yahoo.com.br.

${ }^{5}$ Enfermeira, Mestranda em Enfermagem, Universidade do Estado do Rio de Janeiro, RJ, Brasil. E-mail: mariagazel@hotmail.com.

${ }^{6}$ Enfermeiro, Mestre em Enfermagem, Professor Assistente, Universidade Federal Fluminense, Rio das Ostras, RJ, Brasil. E-mail: professorrlh@uol.com.br.
} 


\section{When IS The END? A narRative ReVieW ON THE TERMination OF THE SCHOOL TERM FOR MENTALLY DISABLED STUDENTS}

The process of inclusion of disabled students is possibly one of the biggest dilemmas faced by professionals in the field of education today. It is necessary to create different educational or assistive devices, due to the termination of the school term, precisely so that future opportunities may be real, and not designed as an exclusionary practice. This article aims to present and understand the concept of specific terminality, allowing reflection on the education of disabled persons. This is a qualitative study, which used the technique of narrative review and methodological contributions. The results indicate the need of effective school termination, which enables social inclusion of disabled people.

Descriptors: Mental Retardation; Education; Review Literature as Topic.

\section{¿CUÁNdo Llega EL FIN? UNA REVISIÓN NARRATIVA SOBRE EL FIN DEL PERÍODO ESCOLAR PARA ALUMNOS DEFICIENTES MENTALES}

El proceso de inclusión de alumnos deficientes posiblemente es uno de los mayores impases enfrentados por los profesionales del área de la educación, en la actualidad. Se hace necesaria la creación de diferentes dispositivos educativos o asistenciales, en faz del fin del período escolar, justamente para que las oportunidades futuras puedan ser reales, y no concebidas como práctica excluyente. Este artículo objetivó presentar y comprender el concepto de fin específico, posibilitando ponderación sobre el proceso educativo de personas deficientes. Se trata de un estudio cualitativo, lo cual utilizó la técnica de revisión narrativa como aporte metodológico. Los resultados apuntan la necesidad de la efectuación del fin escolar, que posibilita la inclusión social de personas deficientes.

Descriptores: Retraso Mental; Educación; Literatura de Revisión como assunto.

\section{Introdução}

Este artigo apresenta uma reflexão acerca das etapas pelas quais passa o aluno deficiente mental no contexto escolar. Aqui se discutirão desde a inclusão, perpassando por sua aplicabilidade, até o momento da chamada terminalidade específica. Atém-se a essa última questão, por se entender a urgência de um questionamento referente à sua eficácia, a qual deve ser focada em alguns objetivos como, por exemplo, o de possibilitar ao deficiente mental a inclusão social através da educação profissional, e não apenas o de ocupar uma vaga no sistema educacional. Vaga essa que, se ocupada de maneira não planejada, poderá não vislumbrar perspectivas de um futuro no qual esse aluno possa ser um trabalhador incluso.
Neste estudo, apresentam-se as etapas de maneira sequenciada, para possibilitar reflexão sobre como tem se dado a terminalidade específica para o deficiente mental, uma vez que é um direito do aluno ter a sua certificação e ser encaminhado a possibilidades futuras de inclusão no mercado de trabalho formal, garantido pelo Conselho Nacional de Educação ${ }^{(1)}$.

Para se compreender melhor o conceito de terminalidade específica para pessoas com deficiências mentais, precisa-se entender como se deu o caminho escolar percorrido por esses alunos, começando pelas tentativas de inclusão no ensino regular. A terminalidade específica deve preocupar todos os envolvidos no processo 
educativo do deficiente mental, compreendidos por professores, gestores, equipe pedagógica, família e demais pessoas preocupadas com o futuro do aluno. Diante do exposto, surgem algumas indagações, tais como: esse aluno está incluído/inserido? Ou, mais uma vez, excluído, sem participação e reconhecimento? O que se espera desse aluno, como incluído? O que se espera da escola como responsável pelo desenvolvimento desse aluno, enquanto responsável pela certificação do deficiente mental? Como desvendar essas situações?

O objeto deste estudo é a terminalidade específica dos estudos para alunos deficientes mentais. Para desenvolvê-lo, utilizou-se a técnica de revisão narrativa, que possibilita a construção de artigos nos quais os autores possam realizar análises e interpretações críticas mais amplas, possibilitando compreender o "estado da arte" de um determinado assunto, sob um ponto de vista teórico ou contextual. As revisões narrativas não necessitam ficar atreladas a informar fontes de informações utilizadas, a metodologia para a busca das referências, nem os critérios utilizados na avaliação e seleção dos trabalhos consultados $^{(2)}$.

Por questões éticas e metodológicas, entretanto, optou-se por citar, ao longo deste trabalho, as fontes que foram utilizadas para a realização do estudo. Inclusive, tal escolha justifica-se para dar mais credibilidade a esse tipo de revisão, pouco explorado na área da educação.

Inclusão

A palavra "inclusão" é a grande temática contemporânea no campo educacional, a qual, no passado, poderia ser considerada uma "problemática solucionada" para as famílias, uma vez que trazia a possibilidade de educação escolar igualitária para seus filhos, compreendida como um paliativo, pois a realidade enfrentada nas escolas fazia com que o professor, muitas vezes, visse a inclusão como algo impossível, até mesmo utópico. No entanto, defende-se a ideia de que não se trata de utopia, uma vez que esse aluno existe concretamente, com as peculiaridades de cada um, sendo considerado em todas as suas manifestações, sejam intelectuais, sociais, culturais ou físicas ${ }^{(3)}$.

A Constituição Federal ${ }^{(4)}$ de 1988 prevê, no Capítulo III, Seção I, Artigo 206, Inciso I, a igualdade de condições para o acesso e permanência na escola. Já o artigo 208, Inciso III, diz que o atendimento educacional especializado em favor dos portadores de deficiência, deve ser realizado, preferencialmente, na rede regular de ensino.

A palavra "preferencialmente", citada acima, pode traduzir uma ideia de não obrigatoriedade, podendo, dessa maneira, minimizar a responsabilidade da escola em receber esse aluno, ou em não assumi-lo, em função de suas dificuldades, o que para alguns seria considerado impossibilidade ou limite, para o desenvolvimento escolar.

Com o passar dos $\operatorname{anos}^{(5)}$, "a limitação antes vista somente como dificuldade exclusiva da pessoa passa a ser observada como limitação da sociedade em oferecer condições que possibilitem a superação de barreiras físicas, econômicas e sociais". Realça-se que as principais barreiras impostas às pessoas com deficiências decorrem de preconceitos e estereótipos socialmente construídos.

Atentando ao artigo 59, da Lei de Diretrizes e Bases da Educação Nacional ${ }^{(6)}$ (LDBEN), verifica-se que é assegurado aos educandos com necessidades especiais o direito a currículos, métodos, técnicas, recursos educativos organizados de maneira específica, a fim de atender às suas necessidades. No Inciso II dessa mesma Lei é assegurada a terminalidade para aqueles que, em virtude de sua deficiência, não puderam atingir o nível exigido para a conclusão do ensino fundamental, bem como é assegurado que os mesmos fazem jus a uma certificação de estudos.

Durante o período de permanência na escola, os alunos deficientes, de acordo com a LDBEN, terão direito a professores com especialização adequada em nível médio ou superior, a fim de ofertarem um atendimento especializado. Entretanto, a referida Lei vislumbra a possibilidade de integração em classes regulares de ensino, o que ocorre nas chamadas escolas inclusivas.

O Conselho Nacional de Educação ${ }^{(1)}$, em seu Artigo $8^{\circ}$, dispõe sobre a flexibilização e adaptações curriculares, as quais devem considerar o significado prático e instrumental dos conteúdos básicos, das metodologias, recursos diferenciados e também sobre o processo avaliativo adequado ao desenvolvimento desses alunos.

No caso da terminalidade, abre-se uma possibilidade de efetivação da integração e do pleno exercício da cidadania por parte da pessoa deficiente, fazendo jus ao título de trabalhador, como proposto na $\operatorname{LDBEN}^{(7)}$. A referida legislação afirma que a educação especial deve vislumbrar possibilidades de inclusão no mercado de trabalho, efetivando a integração na vida em sociedade, gerando condições adequadas de permanência, mediante articulações intersetoriais.

A escola inclusiva requer a efetivação de currículos adequados, sejam eles adaptados ou modificados, assim como prática pedagógica flexível, dessa forma, favorecendo o bom aproveitamento e o chamado ajuste socioeducacional ${ }^{(8)}$.

É importante que o professor esteja atento às inovações que são necessárias para educação de qualidade, inclusive para a própria prática docente. Mudanças deveriam ser entendidas como positivas pelos professores e não desanimadoras. Um bom exemplo seriam as mudanças exigidas nas adaptações curriculares, para possibilitar a permanência do aluno deficiente. O educador embasado em um paradigma inclusivo é aquele mais bem preparado para oferecer ensino de qualidade. Diferente do paradigma especial, o qual o descreve como especialista em determinada deficiência ${ }^{(3)}$.

O ensino balizado na perspectiva inclusiva ressignifica o papel do professor enquanto educador, seja na escola, na educação e em práticas pedagógicas que são usuais no contexto excludente em diversos níveis de ensino. Chamase a atenção para o argumento - frequentemente utilizado por docentes para resistir a algumas práticas inclusivas de que não estão ou não foram preparados para receber alunos com necessidades específicas de aprendizado. Há 
uma reação por parte de alguns docentes, logo no início de suas atividades laborais, ao alegarem que não estão aptos para ensinar alunos com deficiência. Eles têm uma concepção errônea, ao achar que é necessária uma formação prévia, que lhes permita aplicar esquemas de trabalhos pedagogicamente pré-definidos, como se isso fosse a solução para os problemas que presumem encontrar nas escolas ditas inclusivas ${ }^{(3)}$.

Um significativo quantitativo de profissionais crê que sejam necessários um ou mais cursos de extensão ou especialização, o que conferiria a esses profissionais a capacidade de serem professores inclusivos ${ }^{(3)}$. Não se pode conceber a inclusão pela simples existência de uma chamada classe inclusiva, expressa através de um dos tópicos que constam do elenco de um projeto pedagógico da escola, mas quando se entende que incluir requer, além de títulos ou certificações, uma pré-disponibilidade interna muito grande por parte dos docentes e demais membros da equipe pedagógica.

$\mathrm{ALDBEN}^{(8)}$, em seu Artigo 12, chama a atenção para a possibilidade de autonomia por parte da escola, para elaboração de seu Projeto Político Pedagógico, o chamado PPP, visando atender à diversidade sociocultural existente, assim como poder avaliar sua práxis, e vislumbrar uma excelente maneira de iniciar a inclusão, pensando e repensando práticas as quais contemplem as pessoas deficientes através de projetos, debates e capacitações.

Contudo, cabe uma crítica aos projetos político pedagógicos que visam, apenas, esclarecer diretores, professores, coordenadores, funcionários e pais sobre a clientela e os recursos humanos e materiais dos quais a escola dispõe, quando se esperava que tais projetos pudessem ser um instrumento não apenas de organização pedagógica da escola, mas que fossem revistos e modificados, a fim de possibilitar processos de transformação no universo escolar. É no ato de refazer que se vislumbra um futuro compromisso com a formação, propósitos, riscos, promessas e rupturas, confiando-se em que essas não sejam apenas meras palavras, mas que mantenham estreitas ligações com a inclusão( ${ }^{(3)}$.

Em um trabalho acadêmico defendido no ano $2006^{(5)}$, há relato do percurso de trabalho realizado com 26 profissionais de uma escola pública de São Paulo que tinha como objeto de estudo queixas à educação inclusiva. Chegou-se a resultados interessantes, que poderiam servir de base para a reflexão acerca da inclusão de alunos com deficiência. Verificou-se que $28,06 \%$ dos participantes afirmaram a necessidade de suporte/apoio na relação com o aluno deficiente; $13,67 \%$ relataram problemas de comportamento/adaptação dos alunos; $12,59 \%$ justificaram falta de preparo por parte do professor, ao expressaram sentimentos de angústia e de impotência. A pesquisa cita ainda outros fatores, tais como a falta de recursos materiais e de cursos/capacitações mais adequados à realidade dos docentes. No que tange à falta de apoio no processo de inclusão, identificou-se ser essa a principal dificuldade. A pesquisa revelou que a deficiência mental é a que mais preocupa os docentes e a mais prevalente no contexto educacional, provavelmente a que exige o maior número de adaptações, tanto curriculares quanto de atitudes.

A deficiência mental não é sinônimo de incapacidade de aprendizagem. Talvez a criança não aprenda o que o professor espera, não tenha o mesmo ritmo de aprendizado da maioria dos alunos, nem aprenda da mesma maneira, mas, isso, de modo algum significa que ela não seja capaz de aprender ${ }^{(5)}$.

Como visto acima, o ritmo de aprendizagem, para alguns alunos, pode ser mais lento em comparação a outros da mesma idade ou classe/série que não apresentam a mesma deficiência. Caso o ritmo seja mais lento, o aluno pode permanecer por período maior de anos na escola, porém, muitas vezes, isso leva os docentes a pensar que deve ser feito um trabalho de adaptação e que esse seja inserido no projeto pedagógico. Há de se ter o cuidado para que esses alunos não estejam apenas passando pela escola, isto é, estejam apenas por imposição legal e sem nenhuma fundamentação psicopedagógica. A estada desses alunos na escola deve ser marcada pela valorização do potencial individual de cada um, e não meramente pautada numa educação alicerçada em seu déficit. Faz-se necessário acreditar que o deficiente mental tem capacidades e que, muitas vezes, é a sociedade que lhe impõe limites. É preciso extrapolar as barreiras e valorizar a capacidade existente em cada um deles.

De acordo com a pesquisa do Censo Escolar de 2004, a deficiência mental "possui o maior índice de matrículas em Escolas Especiais/Classes Especiais e Escolas Regulares/ Classes Comuns em relação às outras deficiências"(5). Há a necessidade de se elevar e efetivar práticas educacionais direcionadas para os deficientes mentais. O censo revelou que 51,4\% dessas matrículas são de deficientes mentais.

Os dados apresentados servem de base para reforçar a importância de estudos direcionados à terminalidade. Possivelmente, na prática cotidiana, um bom caminho para efetivar a terminalidade seria encaminhar os deficientes mentais à educação profissional ou à continuação dos estudos através da Educação de Jovens e Adultos, conhecida como EJA.

A preocupação quanto ao fim do período escolar para alunos com deficiência mental não é exclusiva de gestores e professores que se veem, às vezes, "perdidos", principalmente no que tange aos aspectos pedagógicos (metodologia, conteúdos, avaliações, atitudes etc.), mas é também objeto de preocupação da família que quer ver seu filho progredir e avançar.

$\mathrm{O}$ avanço no aprendizado de alunos com deficiência mental, em especial o desenvolvimento cognitivo e motor, será facilitado no ensino regular mediante as adaptações curriculares. Através dessas adaptações, sejam elas significativas ou não, de grande ou pequeno porte, pensadas em conjunto (professores, equipe pedagógica e gestores), poderá ser viabilizado o progresso de aprendizagem do aluno.

Com as adaptações curriculares, ele pode até vir a não aprender todos os conteúdos, principalmente os mais abstratos, pode não aprender todas as operações matemáticas ou todas as regras da língua portuguesa, mas ele pode, ao longo de sua permanência na escola, ter uma 
continuidade nos objetivos propostos e conseguir realizar operações simples de matemática e utilizar-se da língua para se comunicar. Porém, a descontinuidade das propostas de adaptações curriculares para o deficiente mental pode gerar possível fracasso da inclusão, transformando o aluno deficiente mental em mais um número na sala de aula, ou seja, não incluído na proposta pedagógica da escola.

\section{A terminalidade dos estudos}

A terminalidade pensada no contexto educacional vislumbra possibilidades, sonhos e perspectivas. É algo esperado, desejado e de sentimento positivo, porém, nem sempre é esse o fim destinado à certificação, quando recebida, pelos alunos com deficiência mental. Lamentavelmente, essa é uma temática contrária às ideologias propostas.

A terminalidade estabelecida através da $\operatorname{LDBEN}^{(8)}$, no Capítulo V, Inciso II do Artigo 59, que trata da Educação Especial, e em conformidade com a Resolução 02/01, do Conselho Nacional de Educação, deve ser concedida aos alunos que comprovadamente demonstrarem não ter se apropriado das competências e habilidades básicas esperadas para o nível de ensino pertinente a sua faixa etária.

Nas Diretrizes Nacionais para a Educação Especial na Educação Básica está explicitada a necessidade de previsão de uma temporalidade de caráter flexível, durante o ano letivo, justamente para atender as necessidades educacionais especiais de alunos com deficiência mental, garantindo que possam concluir, em um período de tempo maior, o currículo previsto para a série/etapa escolar.

Antes da expedição dos documentos que comprovem a certificação escolar, as instituições de ensino deveriam ser orientadas em relação aos procedimentos pedagógicos necessários, ressaltando, inclusive, que o tempo de permanência escolar do aluno deficiente mental foi superior à de seus pares.

A ideologia em torno da terminalidade, bem como a inclusão, parece ser de extrema relevância, tendo uma propriedade e intenção inquestionáveis, para o desenvolvimento do educando. Não seria considerada utópica por alguns profissionais se houvesse uma reestruturação maior, compreendida através de capacitações, investimentos, políticas públicas, dentre outros. Infelizmente, o que se tem constatado é que, na maioria das vezes, o aluno deficiente mental fica por longos anos na escola e, às vezes, sem a devida certificação, a qual poderia lhe garantir continuar seus estudos, seja na Educação de Jovens e Adultos ou na educação profissionalizante. Caso isso ocorresse, alguns alunos poderiam ser inseridos no mercado de trabalho ${ }^{(6)}$.

No relatório individual de alunos indicados à terminalidade, assegurado pela Portaria Conjunta CENP/ COGSP/CEI, de 6 de julho de $2009^{(9)}$, apontam-se dados relevantes, que devem ser destacados na elaboração das propostas pedagógicas. Nele deve constar as adaptações curriculares, de acesso, os objetivos e conteúdos funcionais e práticos, bem como o exercício da autonomia e os critérios de avaliação adotados durante o processo de ensino-aprendizagem.

Destaca-se no Artigo 16, da Resolução 02/01(1), a evidente necessidade de certificação dos alunos, quando as possibilidades de aprendizagem tenham se esgotado. $\mathrm{Na}$ certificação vislumbram-se condições essenciais que devem constar das propostas pedagógicas para o aluno deficiente mental. Se as escolas conseguirem contemplar as prerrogativas necessárias à terminalidade, expressas através do relatório individual do aluno, elas terão desempenhado seu papel na inclusão, gerando oportunidades futuras para o aluno. O deficiente mental precisa ser visto como uma pessoa capaz. A escola pode ter papel fundamental na diminuição de estereótipos e preconceitos que, às vezes, levam algumas pessoas leigas a se afastarem, a ignorá-los e segregá-los ${ }^{(10)}$.

\section{Considerações Finais}

Tendo em vista os ideais sobre a terminalidade, espera-se que práticas educativas ocorram no sentido de não excluir o aluno deficiente mental do convívio social, mas que possibilitem sua inserção no mercado de trabalho, compreendendo-o como cidadão possuidor de direitos igualitários na sociedade.

A terminalidade precisa deixar de ser uma utopia e se transformar em realidade, levando a possibilidades concretas no cotidiano da pessoa deficiente mental, não o remetendo a uma forçada finalização educativa, na qual esse não possa ter asseguradas suas perspectivas e aspirações futuras.

É importante dar mais credibilidade à legislação vigente voltada à Educação, em especial ao artigo 16 do Conselho Nacional de Educação, o qual à educação básica, ou seja, que todas as possibilidades de permanência tenham sido ofertadas a esse aluno na escola. Que os vejam como alunos considerados incluídos, visto terem sido educados em contato direto com os demais alunos, compreendendo suas dificuldades, mas sem fazer dessas, o limite para seu desenvolvimento, para prosseguir.

A inclusão social é uma condição sine qua non para a vida em sociedade e para que o aluno possa ser compreendido como cidadão. $\mathrm{O}$ aluno deficiente não deve ser compreendido apenas através de dados numéricos, expressos através de censos escolares. Ele deve ter garantida a sua participação enquanto um ser ativo na construção de seu futuro.

\section{Referencias}

1. Conselho Nacional de Educação. Portaria Conjunta CENP/COGSP/ CEI, de 6-7-2009 [acesso 25 junho 2010]. Disponível em: http://desaobernardo.edunet.sp.gov.br/ portaria_conjunta_CENP_COGSP_CEI_06_07_09.doc 2. Conselho Nacional de Educação. Resolução CNE/CEB 2/2001. Institui Diretrizes Nacionais para a Educação Especial na Educação Básica. Diário Oficial da União, Brasília, 14 de setembro de 2001. Seção 1E, p. 39-40. [acesso 15 julho 2010]. Disponível em: portal.mec.gov.br/ cne/arquivos/pdf/CEB0201.pdf 
3. Rother ET. Revisão sistemática $\mathrm{x}$ revisão narrativa. Acta Paul Enferm. [periódico na Internet]. abr-jun 2007 [acesso 13 ago 2010] 20(2):v-vi. Disponível em http: //www.scielo.Br/scielo.php? script= sci_ arttext\&pid +S0103-21002007000200001

4. Mantoan MEE. Inclusão Escolar: O que é? Por quê? Como Fazer? 2a ed. São Paulo: Moderna; 2006.

5. Presidência da República (BR). Constituição da República Federativa do Brasil de 1988. Pub. 11 out 1998. [acesso 13 ago 2010]. Disponível em: http://www.planalto. gov.br/ccivil_03/constituicao/constituiçao.htm

6. Prioste CM, Machado MLC, Raiça D. Dez Questões sobre a Educação Inclusiva da pessoa com deficiência mental. São Paulo: Avercamp; 2006.

7. Mendes EG. Perspectivas para a construção da escola inclusiva no Brasil. In: Palhares MS, Martins SC. Escola Inclusiva. São Carlos: EdusCar; 2002.

8. Michels MH, Garcia RMC. A Nova LDB e o processo de integração de sujeitos considerados portadores de deficiência. Ponto de Vista. jul-dez 1999;1(1):30-5.

9. Câmara dos Deputados (BR). A Educação Especial no contexto da Lei de Diretrizes e Bases da Educação. Brasília; 1997.

10. Conselho Nacional de Educação. Portaria Conjunta CENP/COGSP/ CEI, de 6-7-2009 [acesso 25 junho 2010]. Disponível em: http://desaobernardo.edunet.sp.gov.br/ portaria_conjunta_CENP_COGSP_CEI_06_07_09.doc.

\section{Como citar este artigo:}

Elias CSR, Silva LA, Martins MTSL, Ramos NAP, Souza MGG, Hipólito RL. Quando chega o fim? Uma revisão narrativa sobre terminalidade do período escolar para alunos deficientes mentais. SMAD, Rev. Eletrônica Saúde Mental Álcool Drog. (Ed. port.). jan.-abr. 2012 [acesso:

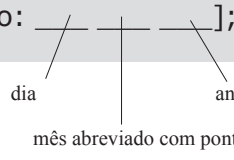
];8(1):48-53. Disponível em: 